\title{
UNDERSTANDING THE RISING POWERS' CONTRIBUTION TO THE SUSTAINABLE DEVELOPMENT GOALS
}

\author{
Rising powers such as Brazil, India and China have been criticised for being
} obstructive in the negotiations on the post-2015 development agenda. The start of the United Nations (UN) negotiations saw high expectations for the role of these countries in shaping the Sustainable Development Goals (SDGs). This leadership has not materialised. However, what appears to be a confrontational style of diplomacy is in fact an assertive affirmation of long-standing principles. Rapid and real progress is being made both in these countries' national frameworks and their international commitments to making the SDGs a reality, and a more nuanced understanding of these countries' positions in the post-2015 process is required.

\section{Challenges to agreeing an SDG framework}

As we approach the three big milestone conferences on global development issues in 2015 Financing for Development (Addis Ababa), the UN Summit on Sustainable Development (New York), and the UNFCCC COP21 (Paris) - understanding the BRICS' (Brazil, Russia, India, China and South Africa) positions on the post-2015 process is fundamental to ensuring the successful creation of a new framework that addresses the structural drivers of poverty, inequality and unsustainable development and meeting the existing Millennium Development Goals (MDGs). A number of stumbling blocks to the establishment of the SDG framework still require resolution, namely: the acceptance of Common but Differentiated Responsibilities (CBDR) as a guiding principle; solid commitments from rich and poor countries alike on financing for development (FFD); clarity on means of implementation and what the global partnership for development will look like.

In stark contrast to the top-down way in which the MDGs were developed, the design of the SDGs has been much more inclusive, which the BRICS and other developing countries see as crucial to ensuring the continued legitimacy of the process. The SDGs were drafted by an inter-governmental Open Working Group (OWG) bringing together 70 UN Member States sharing 30 seats, an innovative arrangement which helped individual countries' perspectives be represented outside of their regional groupings. The OWG included traditional aid-giving countries such as the OECD DAC's members, as well as members of the G77 and China, and the Small Island States. All of the BRICS participated actively in the process, although Russia and South Africa did not have seats in the OWG. The prevailing view from the global South is that whilst somewhat unwieldy, 17 goals and 169 targets should be seen as what it takes to get so many different stakeholders to sit around the table and successfully reach a consensus of sorts.

\section{Brazil and China in the post-2015 process}

Claims that the BRICS are being obstructive, for example on the issue of security and Goal 16 in the SDGs, are worth examining in the broader context of global governance and what might be seen as the unspoken contestation of the universal nature of the SDGs. The G77 and China have consistently called for the reform of the UN Security Council, and of the Bretton Woods institutions, which resulted in International Monetary Fund reform being nominally approved in 2010 before being blocked by the United States (US) Congress. Thus, the BRICS' assertiveness in engaging in global development policy outside of the realms of these institutions should therefore be seen as partly a response to this. A key reason for the BRICS' participation in the post-2015 process was the SDGs' universal nature, which Brazil sees as having lost momentum. The issues which Brazil and other influential middle-income countries (MICs) have emphasised (i.e. consumption patterns, climate change, finance) apply particularly to developed countries. A big concern for MICs is that the SDGs appear to have lost the power to influence the sustainability agenda of developed countries: this is a sticking point for Brazil and others in the G77 who fear developed countries will not accept the implications of a universal development agenda. China's view is more nuanced, and is less focused on the universality of the SDGs and more on the overarching concept of sustainable development, which it refers to as inclusive development. 


\section{Brazil}

Brazil had a key role in shaping the SDGs. It hosted and championed the Rio 92 Earth Summit and the Rio+20 conferences and had representatives on the UN High-Level Panel of Eminent Persons and in the UN Intergovernmental Committee of Experts on Sustainable Development Financing. Whilst some observers expressed their disappointment in Brazil's lack of leadership in the Open Working Group negotiations, it has been vocal in its participation and shown political willingness to contribute to and shape the SDG process. However, developed countries are frustrated that, despite being one of the top ten economies globally, Brazil insists it is still a developing country due to its high levels of inequality and pockets of persistent poverty. China holds a similar position. Developed countries see this as the BRICS shirking their responsibilities for the burden of development. However, the recent climate negotiations in Lima are a good example of Brazil's concerted engagement with the post-2015 process. Brazil proposed a 'concentric differentiation' approach at COP2O, designed to unlock the negotiations on CBDR whilst respecting the original principle behind it. Should this go ahead it may pave the way for the operationalisation of CBDR in the context of the SDGs.

Brazil was a firm supporter of the MDGs, and over the past 15 years achieved seven out of the eight goals, as well as a steady decline in inequality - the Gini coefficient decreased from 0.499 in 2012 to 0.497 in 2013, even as Brazil's growth was slowing. In line with these policy priorities, the issues defended by the Brazilian negotiators centred on poverty eradication, its relationship with inequality; sustainable production and consumption; financing (FFD); and keeping climate change strictly within the UNFCCC process. More controversially, Brazil is keen to avoid what it sees as the securitisation of development through the SDGs. It supports governance as a general principle guiding the SDGs, but is adamant in its refusal to consider security as a stand-alone goal. The Brazil/BRICS position on the issue of security, rule of law and governance has been contested by some in government and civil society and by developed countries and African states. Some civil society organisation observers are challenging Brazil on this, calling for it to heed the relationship between security, social justice and inequality.

The Brazilians are prioritising the 'how' of the SDGs, concentrating on the means of implementation for sustainable development through data disaggregation and exploring how to reutilise the structure of the MDGs as well as Brazil's experience of participatory development in implementation. There are a number of indicators of Brazil's commitment to the post-2015 agenda, including the application of the SDG framework to the design of the forthcoming Pluriannual Plan (PPA), a four-yearly strategic plan which should be approved in August 2015, a full month before the SDGs are approved in September 2015. After Rio+20 the Ministry of Finance also created new structures to address environmental and sustainability issues, and ensured that its work with the World Bank aligned International Development Assistance (IDA) with the Rio Principles, which is visible in the indicators for the last replenishment of IDA. A similar dynamic is evident in the way other ministries engage internationally; in particular, the Ministry of Health with the $\mathrm{WHO}$, and the ministries of Social Development and Agrarian Development with various UN agencies such as the FAO, IFAD, and WFP; as well as the Community of Latin American and Caribbean States (CELAC). Furthermore, the Brazilian Inter-Governmental Working Group (GTI) has set up task-teams to assess how best to adapt the national monitoring and evaluation indicators for the SDGs, looking at what worked with the MDG and national processes. The GTI is working hard to ensure the SDG framework can be appropriated and nationalised, in an attempt to replicate the institutionalisation which helped make the MDGs a success. Based on the legacy of the Earth Summit and Rio+20, Brazil has a vested interest in the success of the SDGs. 


\section{Other rising powers at a glance}

Colombia was instrumental in the creation of the SDGs in their current format. It submitted a paper during the Rio+20 planning process, proposing a set of sustainable development goals which 'would translate the Green Economy and Sustainable Development debate into tangible goals, which would focus the broad debate at a practical level'.

India maintains its historical G77 positioning, and is a strong advocate for the Rio Principles and the principle of CBDR as the fundamental basis for the universality of the SDGs. The Indian Government has been critical of the potential for impact of the 17 goals. It has a large delegation and a strong presence in the negotiations in New York.

South Africa differs somewhat from the other BRICS and many G77 members in the post-2015 process, positioning it with the African Union states in adopting the Common African Position (CAP), which prioritises peace and security as fundamental for development. The emergence of an 'African South' within the G77 represents a marked change in the dynamics of the group, often dominated by bigger players such as Brazil. African countries are carving out a space for their voices to be heard in the UN.

Mexico's growing engagements in international development are indicative of its repositioning on the global development policy landscape. Mexico hosted various events in the context of the post-2015 process, including the regional consultation for civil society groups from Latin America and the Caribbean (2013); the Global Thematic Consultation on Energy and the Post 2015 Development Agenda (2013); and the High-Level Meeting of the Global Partnership for Effective Development Co-operation (GPEDC) in 2014. It was an active participant in the OWG, sharing a seat with Peru, and advocating strongly for tackling inequality, sustainable energy and climate change, as well as other issues of national interest such as indigenous and migrants' rights

\section{China}

China is a success story for the Millennium Development Goals as the first developing country to meet the halving of its poverty rate, which it did ahead of schedule in 2010, succeeding in cutting the incidence of poverty from 10.2 per cent to 2.8 per cent. China is well within reach of meeting all the MDGs but these social developmental achievements are the result of national government policy, and owe little to international frameworks such as the MDGs. China has been proactive in the post-2015 process, starting with the publication of a governmental position paper in 2013 which had poverty reduction and sustainable development at its core, reflecting the focus on social and environmental issues in the government's Five-Year Plan (2011-2015). The recent bilateral China-US climate change agreement, China's growing involvement in global development policy, the creation of the Asian Infrastructure Investment Bank (AllB) and the Silk Road Fund, and the ongoing reform of Chinese cooperation all point to a new phase in China's global diplomacy (and one which Britain has been smart to recognise, as evidenced by its recent membership of the AlIB, much to the US's vocal displeasure). Chinese leadership is seeking to counter Western dominance through active contribution to shaping global development agendas. The changing balance of power on the global landscape requires significant adjustment from developed and developing countries alike. The risk of not finding a way to work together in fora such as the UN is that other regional and bilateral spaces become the place for where policy is actually made, such as the Forum on China-Africa Cooperation (FOCAC), the China-CELAC Forum and the BRICS.

China challenges developed countries such as the UK and the US, which are grappling with domestic and global issues to finding their niche in a changing world order. Even as it rises to become one of the potentially most important poles in an increasingly multipolar world, China is still the largest developing country, and the historical continuity of its positioning with the G77 places it firmly in line with developing and Southern countries. China sees no inherent contradiction in viewing itself as both developing and rising, extremely powerful but also keen to learn from other countries' experiences, and is open about the extent of the developmental issues it is grappling with.

China sees the remit of the SDGs as belonging strictly to discussions on international development; whereas security matters should be exclusively addressed within the bounds of the UN Security Council (UNSC), which rather limits the participation of those who do not have a permanent seat on the UNSC. China has been quick to express its solidarity with the Common African Position - the Chinese Premier's speech to the United Nations General Assembly on the 70th anniversary of the UN focused on peacekeeping and peace and security at length - whilst continuing to advocate for the separation of security and development, a thorn in the side of developed countries in the OWG negotiations. 
from central government. It is likely that energy is being preserved for COP21, where the stakes are seen as being higher due to the potentially binding nature of the agreement. There are some doubts amongst some Chinese academics to the ability of the SDG framework to deliver a global position on achieving sustainability. Like Brazil, their view is that national development policy priorities, frameworks and strategies are the fundamental starting point for any debate on global goals and targets, with the sovereignty of countries central to the framing of cooperation agreements. China supports social, economic and environmental development, which it refers to as inclusive development.

There is speculation that the Chinese government will formally shift its position towards universality as it is currently framed in the SDGs, provided developed countries fully accept extending the concept of CBDR to become an overarching principle of the SDGs. In the words of one Chinese observer, this is still a 'fighting area' in the UN over the coming months, not just with developed countries but also between developing countries such as Brazil and G77 states, although Brazil's proposal for concentric responsibility may offer a way forward.

\section{Recommendations}

1. Global development policy is rapidly shifting. In a time of geopolitical uncertainty, the UN's continued ability to convene the world's countries around the table should be seen as a key opportunity for prospects of global

2. Global policy processes are not always seen as the right fora for binding agreements, as evidenced by the China-US bilateral climate agreement. Cooperation through bilateral channels is one way to build and strengthen relations which can then serve to support processes like the SDGs and contribute to global prospects of economic, social and environmental development.

3. Progress made through the SDG process towards greater equality in how global policy is shaped needs to be maintained and built upon, for example in relation to the long-overdue reform of the Bretton Woods institutions.

4. All countries need to recognise and respect the consensual process in which the proposed 17 goals and 169 targets were arrived at, and that these are aspirational goals which mark the starting point for a universal approach to sustainable development. Countries keen to downsize the 17 goals should be careful not to be seen as trying to steamroll other countries' views.

5. The SDGs' voluntary nature is considered key to ensuring the diversity of countries supporting them, and concerns around their achievability should be mitigated by evidence that a willingness to set ambitious goals is also representative of commitment. peace and prosperity.

\section{Further reading}

Allouche, J. (2015)

'Sustainable Development Goals Must Consider Security, Justice and Inequality to

Achieve Social Justice', IDS

Policy Briefing 88, Brighton: IDS

United Nations (2015)

Intergovernmental

Negotiations on the Post-

2015 Development Agenda,

Elements Paper, New York: UN

Saad, L. (2015) Brazil and the Post-2015 Sustainable Development Goal Agenda:

What Has it Been Defending

So Far?, Rio de Janeiro:

World Centre for Sustainable Development ( $\mathrm{RIO}+)$

Fues, T. and Ye, J. (eds) (2014) United Nations Post-2015

Agenda for Global

Development: Perspectives

from China and Europe,

Bonn: German Development Institute

\section{Credits}

This Rapid Response Briefing was written by Jennifer Constantine (Research Consultant, IDS Centre for Rising Powers and Global Development, Sussex) and Márcio Pontual (Senior Policy Analyst, World Centre for Sustainable Development $(\mathrm{RIO}+$ )

The opinions expressed are those of the authors and do not necessarily reflect the views of IDS or of the World Centre for Sustainable Development (RIO+).

Readers are encouraged to quote and reproduce material from issues of Rapid Response Briefings in their own publication. In return, IDS and the $\mathrm{RIO}+$ Centre request due acknowledgement and quotes to be referenced as above.

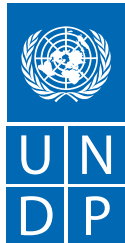

Institute of Development Studies

Empowered lives. Resilient nations.

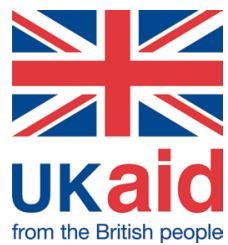

from the British people

IDS Rapid Response Briefings are published by the Institute of Development Studies and aim to provide high-level analysis of rapidly emerging and unexpected global events and their impact on development policy and practice. To subscribe: www.ids.ac.uk/idsrapidresponsebriefings

Institute of Development Studies, Brighton BN1 9RE UK

T +44 (0) 1273606261 F + 44 (0) 1273621202 E ids@ids.ac.uk W www.ids.ac.uk

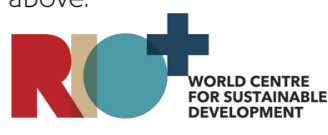

The material has been funded by UK aid from the UK Government and the World Centre for Sustainable Development $(\mathrm{RIO}+$ ). However the views expressed do not necessarily reflect the UK Government's official policies or the views of the United Nations Agencies or Member States.

(c) Institute of Development Studies and World Centre for Sustainable Development (RIO+), 2015 